\title{
Influences on Early and Medium-Term Survival Following Surgical Repair of the Aortic Arch
}

\author{
Mohamad Bashir, MD, MRCS*, Mark Field, DPhil, FRCS(CTh), Matthew Shaw, MSC, \\ Matthew Fok, MBBS, Deborah Harrington, MD, FRCS(CTh), Manoj Kuduvalli, MCh, FRCS(CTh), \\ Aung Oo
}

Thoracic Aortic Aneurysm Service, Liverpool Heart and Chest Hospital, Liverpool, United Kingdom

\begin{abstract}
Objectives: It is now well established by many groups that surgery on the aortic arch may be achieved with consistently low morbidity and mortality along with relatively good survival compared to estimated natural history for a number of aortic arch pathologies. The objectives of this study were to: 1) report, compare, and analyze our morbidity and mortality outcomes for hemiarch and total aortic arch surgery; 2) examine the survival benefit of hemiarch and total aortic arch surgery compared to age- and sex-matched controls; and 3) define factors which influence survival in these two groups and, in particular, identify those that are modifiable and potentially actionable. Methods: Outcomes from patients undergoing surgical resection of both hemiarch and total aortic arch at the Liverpool Heart and Chest Hospital between June 1999 and December 2012 were examined in a retrospective analysis of data collected for The Society for Cardiothoracic Surgeons (UK). Results: Over the period studied, a total of 1240 patients underwent aortic surgery, from which 287 were identified as having undergone hemi to total aortic arch surgery under deep or moderate hypothermic circulatory arrest. Twenty three percent of patients' surgeries were nonelective. The median age at the time of patients undergoing elective hemiarch was 64.3 years and total arch was 65.3 years $(P=0.25)$, with $40.1 \%$ being female in the entire group. A total of $\mathbf{1 4 0}$ patients underwent elective hemiarch replacement, while 81 underwent elective total arch replacement. Etiology of the aortic pathology was degenerative in $\mathbf{5 1 . 2 \%}$ of the two groups, with $\mathbf{8 7 . 1 \%}$ requiring aortic valve repair in the elective hemiarch group and $64.2 \%$ in the elective total arch group $(P<0.001)$. Elective in-hospital mortality was $\mathbf{2 . 1 \%}$ in the hemiarch group and
\end{abstract}

6.2\% $(P=0.15)$ in the total arch group with corresponding rates of stroke $(2.9 \%$ versus $4.9 \%, P=0.47)$, renal failure (4.3\% versus $6.2 \%, P=0.54)$, reexploration for bleeding (4.3\% versus $4.9 \%, P>0.99)$, and prolonged ventilation (8.6\% versus $16.1 \%, P=0.09$ ). Overall mortality was $20.9 \%$ at 5 years, while it was $15.7 \%$ in the elective hemiarch and $\mathbf{2 5 . 9 \%}$ in the total arch group $(P=\mathbf{0 . 0 6 5})$. Process control charts demonstrated stability of annualized mortality outcomes over the study period. Survival curve was flat and parallel compared to age- and sex-matched controls beyond $\mathbf{2}$ years. Multivariate analysis demonstrated the following independent factors associated with survival: renal dysfunction [hazard ratio $(H R)=3.11 ; 95 \%$ confidence interval $(\mathrm{Cl})=1.44-6.73]$, New York Heart Association (NYHA) class $\geq$ III (HR $=2.25 ; 95 \% \mathrm{Cl}=1.38-3.67)$, circulatory arrest time $>100$ minutes $(\mathrm{HR}=2.92 ; 95 \% \mathrm{Cl}=1.57-$ 5.43), peripheral vascular disease $(\mathrm{HR}=2.44 ; 95 \% \mathrm{Cl}=$ 1.25-4.74), and concomitant coronary artery bypass graft operation ( $\mathrm{HR}=2.14 ; 95 \% \mathrm{Cl}=1.20-3.80)$. Conclusions: Morbidity, mortality, and medium-term survival were not statistically different for patients undergoing elective hemi-aortic arch and total aortic arch surgery. The survival curve in this group of patients is flat and parallel to sex- and age-matched controls beyond 2 years. Multivariate analysis identified independent influences on survival as renal dysfunction, NYHA class $\geq \mathrm{III}$, circulatory arrest time (> $100 \mathrm{~min}$ ), peripheral vascular disease, and concomitant coronary artery bypass grafting. Focus on preoperative optimization of some of these variables may positively influence long-term survival.

Copyright @ 2014 Science International Corp.

${ }^{*}$ Corresponding author:

Mohamad Bashir, MD, MRCS

Thoracic Aortic Aneurysm Service

Liverpool Heart and Chest Hospital

Thomas Drive

L14 3PE

United Kingdom

Tel: +441512281616, Fax: +441516001254, E-Mail: drmbashir@mail.com 


\section{Key Words}

Aneurysm - Aortic arch - Aneurysm surgery - Survival • Long-term survival

\section{Introduction}

Surgery to replace the proximal or total aortic arch has become relatively commonplace, with many examples of international centers publishing excellent morbidity and mortality outcomes in large series [1-4] compared with the very early series [5]. Underpinning these patient outcomes are a host of improvements in surgery, anesthesia, nursing, perfusion, and intensive care, all well described by Coselli and LeMaire [6] in Aortic Arch Surgery: Principles, Strategies and Outcomes. This success with clinical morbidity and mortality outcomes has allowed the development of more sophisticated quality measures of the "process" and "structure" of care delivered by institutions published in the form of guidelines on performing and reporting of thoracic aortic surgery [7]. However, reporting of contemporary survival following aortic arch surgery, and the factors which influence it, remains limited $[8,9]$. This work has three aims: 1 ) report, compare and analyze our morbidity and mortality outcomes for hemiarch and total aortic arch surgery; 2) examine the survival benefit of hemiarch and total aortic arch surgery compared to age- and sex-matched controls; and 3) define factors which influence survival in these two groups and, in particular, identify those that are modifiable and potentially actionable.

\section{Methods}

\section{Patient Population and Data}

We performed a retrospective study on 287 consecutive patients who underwent aortic arch surgery at Liverpool Heart and Chest Hospital between June 15, 1999 and December 31, 2012. All relevant clinical data were collected prospectively and entered into a local hospital database from which, periodically, core datasets were validated and submitted to The Society for Cardiothoracic Surgery (UK). In brief, for each operation, a dataset was collected that included relevant demographics, indicators of disease severity, acuity, comorbidities, and procedural details, along with all relevant in-hospital outcomes. Outcomes evaluated for the purposes of this study include in-hospital reoperations for bleeding, sternal wound infections, neurological and renal complications, postoperative ventilation times, and both in-hospital and follow-up mortality.
Variables Documented and Definitions

1) Preoperative variables

a. Current smoker: Smoking within six weeks of the operation.

b. Diabetes: Diagnosis of diet, tablet or insulin controlled diabetes.

c. Hypercholesterolemia: Diagnosed with cholesterol over $5.0 \mathrm{mmol} / \mathrm{L}$ or on drug treatment.

d. Hypertension: Diagnosed with hypertension (blood pressure $>139 / 89 \mathrm{mmHg}$ ) or on antihypertensive treatment.

e. Cerebrovascular disease: The presence of carotid artery disease, chronic neurological injury, or a history of transient ischemic attack (TIA) or cerebrovascular accident (CVA).

f. Respiratory disease: Diagnosed with a respiratory disease (i.e., asthma, emphysema, bronchiectasis, chronic obstructive pulmonary disease), on treatment (i.e., inhalers) or impaired pulmonary function tests.

g. Peripheral vascular disease: Diagnosed with peripheral vascular disease on the basis of symptoms (claudication), previous intervention, or evidence of stenotic disease.

h. Renal dysfunction: The definition of renal failure has changed over time. Over the last 3 years we have recorded eGFR (estimated glomerular filtration rate) as well as the presence of established renal failure and dialysis. An eGFR $<89 \mathrm{~mL} / \mathrm{min} / 1.73 \mathrm{~m}^{2}$ is considered as renal dysfunction (Chronic Kidney Disease). Prior to this, we recorded renal dysfunction as a creatinine value greater than $200 \mu \mathrm{mol} / \mathrm{L}$ and as established renal failure with dialysis.

i. Previous cardiac surgery: Previous sternotomy for any reason.

2) Postoperative variables

a. Intubation time (hours): Presence of endotracheal tube with supported respiratory effort.

b. Intensive Therapy Unit (ITU) stay (days): Care within our Critical Care Area which includes 1:1 nursing care as "intensive care" or 2:1 nursing as "high dependency care."

c. Postoperative stay (days): Number of days within the hospital setting from the day after surgery.

d. Acute renal failure: Postoperative requirement for hemofiltration.

e. Deep sternal wound infection: This is defined as wound dehiscence to the sternal plate with a positive wound culture. It excludes simple superficial wound infections and aseptic mechanical dehiscence.

f. Reexploration for bleeding: This is defined as resternotomy and exploration in the acute postoperative period for bleeding and/or evidence of tamponade.

g. All stroke:

i) CVA, diagnosed clinically or on imaging. 
ii) TIA, diagnosed as clinical evidence of neurological impairment with return of function within 24 hours.

h. Confusion: Acute confusional state diagnosed clinically.

\section{Operative Techniques}

Definitions. To allow an understanding of the extent of resection and reconstruction, we have defined the following terms:

1. Hemiarch surgery. Hemiarch surgery or proximal arch surgery is performed as either a "simple" hemiarch or a "deep" hemiarch. In simple hemiarch surgery, under deep hypothermic circulatory arrest, the arch is resected in a line from the origin of the brachiocephalic artery to the apex of the underside of the arch opposite the left subclavian artery. In deep hemiarch surgery, the entire anterior and posterior wall of the arch is removed leaving an effective Carrel patch of arch vessels connected via a "bridge" of aorta to the descending thoracic aorta. In this study, these two groups have been amalgamated as historical records do not make this distinction. Simple open distal anastomosis under deep hypothermic circulatory arrest has been excluded. Patients undergoing simple open distal anastomosis for acute Type A repair (137 additional cases during this period) have been excluded.

2. Total arch surgery. We have defined total arch surgery as that occurring under deep hypothermic circulatory arrest and involving resection of the arch such that at least one of the great vessels requires reimplantation. Arch vessels were anastomosed either separately or as a Carrel patch. This simple definition was chosen to avoid subclassification of the myriad of permutations of aortic arch surgery. A number of patients who underwent total aortic arch replacement also underwent placement of a conventional elephant trunk using an $8 \mathrm{~cm}$ graft in preparation for possible second stage procedures. In addition, in the latter half of the series, a number of patients underwent placement of a "frozen elephant trunk" using either an EVITA Open Plus Hybrid Stent Graft (Jotec, GmbH, Hechingen, Germany) or a Thoraflex device (Vascutek Terumo Thoraflex Hybrid Stent Graft; Vascutek, Renfrewshire, UK). These devices were only deployed in aneurysms in which there was no chronic dissection or evidence of connective tissue disorder. In addition, they were only deployed in patients who had proximal descending thoracic aneurysms with suitable distal landing zones. Our operative techniques have evolved through the study period as technology and experience have shaped our approach. Below is a general approach to our operations. It is relevant to say that between 1999 and 2007, operations were performed by all surgeons within the center, but principal activity was by a single subspecialized surgeon (Mr Abbas Rashid). After 2007, this same principal surgeon and 4 others subspecialized in aortic surgery (D.H., M.F., M.K., and A.O.) performed the operations. A separate analysis (Appendices) has shown no significant change in outcomes from this transition.

- Incisions. All elective operations were performed through a midline and full sternotomy. In a very small number of emergencies we used either a clamshell [1] or lateral extension to a sternotomy incision [1].
- Cannulation options. A myriad of cannulation techniques were used depending on the anatomy, pathology and available imaging.

- Arterial cannulation. Arterial cannulation of either the ascending aorta, arch of the aorta, femoral artery, or axillary arteries was performed. In a limited number of emergency operations the left ventricular apex was cannulated. All cannulations via the axillary artery were through an anastomosed $8 \mathrm{~mm}$ graft.

- Venous cannulation. Venous drainage was achieved via the right atrial appendage, bicaval cannulation, main pulmonary artery, or femoral vein.

- Venting. Venting of the heart was performed either through the right superior pulmonary vein, main pulmonary artery, or left ventricle (LV) apex via a mini left thoracotomy.

- Conduct of cardiopulmonary bypass. Cardiopulmonary bypass was initiated following full heparinization (300 $\mathrm{U} / \mathrm{kg}$ ) to an activated clotting time $>450$, and during active cooling, alpha stat was maintained. Warming was commenced ensuring no excessive differential between peripheral and core temperatures.

- Cardioplegia. Intermittent cold blood cardioplegia was administered anterogradely at induction and retrogradely during maintenance. Anterograde cardioplegia was supplemented into the right coronary system throughout cases where possible. A "hot shot" of warm blood cardioplegia was administered prior to reflow.

- Monitoring. It is our practice to monitor a radial and femoral arterial trace as well as central venous cannulation and central venous pressure. A nasopharyngeal and bladder/rectal catheter are used to monitor temperature. Near infrared spectroscopy (NIRS) was employed beginning in 2008. Transeosophageal echocardiography is routinely utilized unless contraindicated.

- Brain protection. Our approach to neuroprotection is centered around deep hypothermic circulatory arrest; however, adjuncts include $\mathrm{CO}_{2}$ flooding of operative field, packing of head in ice, phenobarbitone prior to circulatory arrest, and supplementary cerebral perfusion as indicated below:

- Anterograde cerebral perfusion. This is administered in total arch surgery. Cold blood is administered via the head and neck vessels directly or via clamping of the brachiocephalic artery and perfusing the axillary artery. The left subclavian artery is temporarily occluded or may be perfused if NIRS is suboptimal. Target flows of $10 \mathrm{~mL} / \mathrm{kg} / \mathrm{min}$ are used; however, this is modified according to perfusion pressure (target mean, 50-60 $\mathrm{mm} \mathrm{Hg}$ ) and NIRS response.

- Retrograde cerebral perfusion. This technique is used for simple hemiarch surgery or acute pathologies where tissue quality of arch vessels may be poor. The superior vena cava (SVC) is cannulated with a 15 French cannula and a small clamp placed between SVC and right atrial appendage. Flow is commenced at $10 \mathrm{~mL} / \mathrm{kg} / \mathrm{min}$ aiming 
for a central venous pressure (CVP) between 25 and 50 $\mathrm{mm} \mathrm{Hg}$ and an acceptable NIRS reading.

- Temperature: Our core (urinary or rectal) target temperatures for hemiarch and total arch surgery have evolved over the time of the study. During early periods, target temperature for all procedures was less than $18^{\circ} \mathrm{C}$ (deep hypothermia [10]). Currently, our typical target for an elective hemiarch is $25^{\circ} \mathrm{C}$ (moderate hypothermia), elective total arch is $20^{\circ} \mathrm{C}$ (moderate hypothermia), and for emergency cases, $20^{\circ} \mathrm{C}$. Rewarming was aided with external warmers.

\section{Preoperative and Postoperative Criteria}

Indications for surgery. Indications for isolated elective aortic aneurysm surgery were: aneurysmal size greater than $5.5 \mathrm{~cm}$ in nonconnective tissue disorders, size greater than $4.5 \mathrm{~cm}$ with connective tissue disorders. Attributable symptoms were an indication for surgery. Other indications were acute aortic syndromes, infection, fistula, and pseudoaneurysms. In patients in whom the principal indication for surgery was severe disease in the aortic valve, mitral valve, or tricuspid valve and/or coronaries, the threshold for intervention on the aorta was lowered to $4.0-4.5 \mathrm{~cm}$. Similarly, when the primary indication for surgery was the aorta, the threshold for cardiac intervention was lowered; i.e., moderate aortic valve disease, one and two vessel or proximal left anterior descending coronary artery disease. Nonelective surgery was performed based on the presence of acute aortic syndrome or decompensation of nonaortic cardiac-related factors such as aortic valve disease and pulmonary edema or coronary disease with recent non-ST elevation myocardial infarction. We currently adhere to the American Heart Association Guidelines [11] on indications for aortic surgery which, although presented in 2009, broadly reflected our practice prior to publication.

Patient follow-Up. To establish follow-up vital status, patient records were linked to the national Personal Demographic Service (PDS). Patients were matched to the PDS (http:// systems.hscic.gov.uk/demographics/pds) based on National Health Service number, patient name and date of birth, gender, and postcode.

\section{Statistical Methods}

Continuous data that are not normally distributed are reported as median ( $25^{\text {th }}$ percentile, $75^{\text {th }}$ percentile) with Wilcoxon's signed rank test used for comparisons. Categorical variables are shown as frequency and percentage, while comparisons are made with chi-square $\left(\chi^{2}\right)$ tests and Fisher's exact tests as appropriate. Follow-up mortality rates are presented using the Kaplan-Meier method [12] and comparisons are made using the log-rank test. Cox proportional hazards analysis with forward stepwise selection of covariates was used to calculate adjusted hazard ratios (HRs). Limits for entry to and removal from the model were set at $P<0.10$ and $P>0.05$, respectively. In all cases a $p$-value less than 0.05 was considered significant. All statistical analyses were performed with SAS for Windows Version 9.2 (SAS Institute, Cary, NC, USA).

\section{Results}

\section{Demographic Data}

Within the study period we performed a total of 1240 operations on thoracic aortic aneurysms, of which 287 involved the aortic arch and circulatory arrest and were included in this study. Preoperative patient characteristics, including comorbidities and disease etiology, are presented in Table 1, along with operative data. "All AAR" (all aortic arch Aneurysms, $n=287$ ) is presented in column 1 , followed by a spilt of "Elective HAAR" (elective hemi-aortic arch resection) and "Elective TAAR" (elective total aortic arch resection). Nonelective patients undergoing $\operatorname{HAAR}(n=30)$ and TAAR $(n=36)$ are described in Table 2.

\section{Comorbidities}

Of 287 patients included in the present study, 115 (40.1\%) of patients were female. Median age was 63.7 years. A total of $76(26.5 \%)$ patients had a New York Heart Association (NYHA) class $\geq$ III, 100 (34.8\%) suffered from respiratory disease, and 48 (16.7\%) had undergone a surgical cardiac procedure in the past. There were no major differences in comorbidity as defined between elective hemiarch and total aortic arch patients apart from a slightly higher incidence of peripheral vascular disease in the elective total arch group $(P<0.03)$. Also, previous cardiac surgery was more common in the elective TAAR group (30.9\%) versus the elective HAAR group (10\%, $P<0.001)$. In the nonelective cohort, all variables were similar apart from a significantly higher incidence of current smoking in the TAAR group (33.3\%) versus the HAAR group (6.7\%, $P<0.008)$.

\section{Etiology}

A total of $147(51.2 \%)$ patients had simple agerelated degenerative disease in which we also included atherosclerotic aneurysms and bicuspid valve syndrome-related aneurysms. Of these, 138 (48.1\%) were nondegenerative disease including such diagnoses as Marfan syndrome, Ehlers-Danlos syndrome, Loeys-Dietz syndrome, infection, inflammation, and pseudoaneurysms. Two patients had iatrogenic disease. Etiology was poorly specified in our database, principally because it is often uncertain, and in $13.6 \%$, etiology was not recorded. There was no significant difference between the TAAR and HAAR elective groups. 
Table 1. Pre- and Perioperative Patient Data in All Patients and Elective Hemi-aortic Arch Repair (HAAR) and Total Aortic Arch Repair (TAAR)

\begin{tabular}{|c|c|c|c|c|}
\hline Variables & All AAR $(n=287)$ & $\begin{array}{l}\text { Elective HAAR } \\
(n=140)\end{array}$ & $\begin{array}{l}\text { Elective TAAR } \\
(n=81)\end{array}$ & $p$-value \\
\hline Age at operation (years) & $63.7(52.4,71.5)$ & $64.3(53.7,71.9)$ & $65.3(46.6,72.1)$ & 0.25 \\
\hline Female gender & $115(40.1)$ & $48(34.3)$ & $40(49.4)$ & 0.03 \\
\hline \multicolumn{5}{|l|}{ Comorbidities } \\
\hline Body mass index $\left(\mathrm{kg} / \mathrm{m}^{2}\right)$ & $26.9(24.3,30.1)$ & $27.5(24.9,30.4)$ & $26.0(23.2,29.3)$ & 0.03 \\
\hline Left ventricular ejection fraction $<50 \%$ & $58(20.2)$ & $31(22.1)$ & $9(11.1)$ & 0.04 \\
\hline NYHA class $\geq \mathrm{III}$ & $76(26.5)$ & $41(29.3)$ & $20(24.7)$ & 0.46 \\
\hline Current smoker & 39 (13.6) & $16(11.4)$ & $9(11.1)$ & 0.94 \\
\hline Diabetes & $16(5.6)$ & $8(5.7)$ & $4(4.9)$ & $>0.99$ \\
\hline Hypercholesterolemia & $133(46.3)$ & $77(55.0)$ & $36(44.4)$ & 0.13 \\
\hline Hypertension & $159(55.4)$ & $76(54.3)$ & $47(58.0)$ & 0.59 \\
\hline Cerebrovascular disease & $23(8.0)$ & $12(8.6)$ & $6(7.4)$ & 0.76 \\
\hline Respiratory disease & $100(34.8)$ & $52(37.1)$ & $34(42.0)$ & 0.48 \\
\hline Peripheral vascular disease & $21(7.3)$ & $6(4.3)$ & $10(12.4)$ & 0.03 \\
\hline Renal dysfunction & $17(5.9)$ & $3(2.1)$ & $3(3.7)$ & 0.67 \\
\hline Previous cardiac surgery & $48(16.7)$ & $14(10.0)$ & $25(30.9)$ & $<0.001$ \\
\hline \multicolumn{5}{|l|}{ Etiology } \\
\hline Degenerative & $147(51.2)$ & $72(51.4)$ & $44(54.3)$ & 0.68 \\
\hline Nondegenerative & $138(48.1)$ & $67(47.9)$ & $37(45.7)$ & 0.75 \\
\hline latrogenic & $2(0.7)$ & $1(0.7)$ & $0(0)$ & $>0.99$ \\
\hline \multicolumn{5}{|l|}{ Priority } \\
\hline Nonelective procedure & $66(23.0 \%)$ & & & \\
\hline \multicolumn{5}{|l|}{ Extent of arch } \\
\hline Total arch & $117(40.8)$ & & $81(100)$ & \\
\hline Hemiarch & $170(59.2)$ & $140(100)$ & & \\
\hline \multicolumn{5}{|l|}{ Concomitant procedures } \\
\hline Aortic valve replacement & $220(76.7)$ & $122(87.1)$ & $52(64.2)$ & $<0.001$ \\
\hline Mitral valve replacement/repair & $4(1.4)$ & $2(1.4)$ & $1(1.2)$ & $>0.99$ \\
\hline Tricuspid valve & $2(0.7)$ & $1(0.7)$ & $1(1.2)$ & $>0.99$ \\
\hline Pulmonary valve & $1(0.4)$ & $0(0)$ & $1(1.2)$ & $>0.99$ \\
\hline CABG & $46(16.0)$ & $26(18.6)$ & $10(12.4)$ & 0.23 \\
\hline Aortic root & $220(76.7)$ & $114(81.4)$ & $58(71.6)$ & 0.09 \\
\hline Thoracic aorta & $18(6.3)$ & $1(0.7)$ & $2(2.5)$ & 0.56 \\
\hline \multicolumn{5}{|l|}{ Operative times } \\
\hline Circulatory arrest & $38(24,68)$ & $28(20,34.5)$ & $68(45,99)$ & $<0.001$ \\
\hline Cardiopulmonary bypass & $330(272,394)$ & $299(256,341)$ & $358(280,434)$ & $<0.001$ \\
\hline Aortic crossclamp & $185(140,238)$ & $174(138,207)$ & $201(135.5,267.5)$ & 0.02 \\
\hline
\end{tabular}

Categorical variables shown as $n(\%)$, continuous variables shown as median (25 ${ }^{\text {th }}$ percentile, $75^{\text {th }}$ percentile). NYHA, New York Heart Association; CABG, coronary artery bypass graft.

\section{Concomitant Procedures}

A high proportion of patients required intervention on the aortic valve (76.7\%), and this was significantly different between the two elective groups (HAAR, 87.1\%; TAAR, 64.2\%, $P<0.001)$. This was typically associated with aortic root replacement in the two groups together (76.7\%), although this was not statistically different between the two elective groups (Table 1). A similar trend was observed in the nonelective cohort (Table 2). Coro- nary artery bypass graft (CABG) was required in 16\% of the entire group, and this was not significantly different between elective HAAR and TAAR.

\section{Preoperative Outcomes}

Non-normally distributed variables are shown as median (interquartile range); thus, time on cardiopulmonary bypass was $330(272,394)$ min (for completeness, the mean \pm standard deviation (SD) was $337.5 \pm$ 
Table 2. Pre- and Perioperative Patient Data in Nonelective Hemi-aortic Arch Repair (HAAR) and Total Arch Repair (TAAR)

\begin{tabular}{|c|c|c|c|}
\hline Variables & $\begin{array}{l}\text { Nonelective HAAR } \\
(n=30)\end{array}$ & $\begin{array}{l}\text { Nonelective TAAR } \\
(n=36)\end{array}$ & $p$-value \\
\hline Age at operation (years) & $60.6(52.1,74.3)$ & $59.3(53.1,67.2)$ & 0.58 \\
\hline Female gender & $10(33.3)$ & $17(47.2)$ & 0.25 \\
\hline \multicolumn{4}{|l|}{ Comorbidities } \\
\hline Body mass index $\left(\mathrm{kg} / \mathrm{m}^{2}\right)$ & $27.8(24.2,31.6)$ & $26.7(24.1,29.0)$ & 0.28 \\
\hline Left ventricular ejection fraction $<50 \%$ & $10(33.3)$ & $8(22.2)$ & 0.31 \\
\hline NYHA class $\geq \mathrm{III}$ & $8(26.7)$ & $7(19.4)$ & 0.49 \\
\hline Current smoker & $2(6.7)$ & $12(33.3)$ & 0.008 \\
\hline Diabetes & $2(6.7)$ & $2(5.6)$ & $>0.99$ \\
\hline Hypercholesterolaemia & $7(23.3)$ & $13(36.1)$ & 0.26 \\
\hline Hypertension & $16(53.3)$ & $20(55.6)$ & 0.86 \\
\hline Cerebrovascular disease & $3(10.0)$ & $2(5.6)$ & 0.65 \\
\hline Respiratory disease & $9(30.0)$ & $5(13.9)$ & 0.11 \\
\hline Peripheral vascular disease & $4(13.3)$ & $1(2.8)$ & 0.17 \\
\hline Renal dysfunction & $6(20.0)$ & $5(13.9)$ & 0.51 \\
\hline Previous cardiac surgery & $4(13.3)$ & $5(13.9)$ & $>0.99$ \\
\hline \multicolumn{4}{|l|}{ Etiology } \\
\hline Degenerative & $13(43.3)$ & $18(50.0)$ & 0.59 \\
\hline Nondegenerative & $17(56.7)$ & $17(47.2)$ & 0.44 \\
\hline latrogenic & $0(0)$ & $1(2.8)$ & $>0.99$ \\
\hline \multicolumn{4}{|l|}{ Concomitant procedures } \\
\hline Aortic valve replacement & $24(80.0)$ & $22(61.1)$ & 0.10 \\
\hline Mitral valve replacement/repair & $0(0)$ & $1(2.8)$ & $>0.99$ \\
\hline Tricuspid valve & $0(0)$ & $0(0)$ & \\
\hline Pulmonary valve & $0(0)$ & $0(0)$ & \\
\hline CABG & $5(16.7)$ & $5(13.9)$ & $>0.99$ \\
\hline Aortic root & $22(73.3)$ & $26(72.2)$ & 0.92 \\
\hline Thoracic aorta & $0(0)$ & $1(2.8)$ & $>0.99$ \\
\hline \multicolumn{4}{|l|}{ Operative times } \\
\hline Circulatory arrest & $44(25,56)$ & $79.5(52,114)$ & $<0.001$ \\
\hline Cardiopulmonary bypass & $340(283,440)$ & $399(348.5,473)$ & 0.01 \\
\hline Aortic crossclamp & $184(147,207)$ & $223(157,309)$ & 0.04 \\
\hline
\end{tabular}

NYHA, New York Heart Association; CABG, coronary artery bypass graft.

$98.9 \mathrm{~min})$. Similarly, time for circulatory arrest was 38 $(24,68 ; 50 \pm 38.5) \mathrm{min}$. Cardiopulmonary bypass time and circulatory arrest time were significantly longer in the TAAR group than in the HAAR group for both elective and nonelective cohorts.

\section{In-Hospital and Survival Outcomes}

Median (interquartile range; mean \pm SD) stay in intensive care was $3(2,6 ; 6.4 \pm 10.7)$ days, while overall postoperative length of stay in hospital was $11(8,17 ; 15.2 \pm 15.4)$ days. A total of 35 (12.2\%) patients remained on mechanically assisted ventilation for more than 48 hours, 21 (7.3\%) suffered acute renal failure, $18(6.3 \%)$ patients required a reexploration for bleeding, 16 (5.6\%) patients suffered a stroke [CVA $=13(4.5 \%)$, TIA $=3(1.1 \%)], 19$ (6.6\%) patients experienced postoperative confusion, and there was $1(0.7 \%)$ deep sternal wound infection. A total of $23(8.0 \%)$ patients died inhospital, and survival at 1,3 and 5 years was $87.5 \%$, $80.8 \%$, and $79.1 \%$, respectively. The mean (+/- standard error) survival period was 3.9 (0.12) years.

When looking at elective HAAR versus TAAR, the ITU length of stay was significantly longer in the latter group; however, key outcomes such as mortality, stroke, acute renal failure, prolonged ventilation, reintubation, and reexploration for bleeding did not reach statistical significance. In-hospital mortality in 
Table 3. In-Hospital and Follow-up Outcomes in All Patients and Elective Hemi-aortic Arch Repair (HAAR) and Total Aortic Arch Repair (TAAR)

\begin{tabular}{|c|c|c|c|c|}
\hline Variables & $\begin{array}{l}\text { All AAR } \\
(n=287) \\
\end{array}$ & $\begin{array}{l}\text { Elective HAAR } \\
(n=140)\end{array}$ & $\begin{array}{l}\text { Elective TAAR } \\
(n=81)\end{array}$ & $p$-value \\
\hline Intubation time (hours) & $16(11,28)$ & $16(10.5,23)$ & $16(12,38)$ & 0.17 \\
\hline ITU stay (days) & $3(2,6)$ & $2(1,4)$ & $4(2,7)$ & $<0.001$ \\
\hline Postoperative stay (days) & $11(8,17)$ & $10(7,14)$ & $12(9,21)$ & $<0.001$ \\
\hline Re-intubation & $22(7.7)$ & $6(4.3)$ & $9(11.1)$ & 0.052 \\
\hline Prolonged ventilation ( $>48 \mathrm{~h}$ ) & $35(12.2)$ & $12(8.6)$ & $13(16.1)$ & 0.09 \\
\hline Acute renal failure & $21(7.3)$ & $6(4.3)$ & $5(6.2)$ & 0.54 \\
\hline Deep sternal wound infection & $1(0.4)$ & $0(0)$ & $1(1.2)$ & 0.37 \\
\hline Reexploration for bleeding & $18(6.3)$ & $6(4.3)$ & $4(4.9)$ & $>0.99$ \\
\hline All stroke & $16(5.6)$ & $4(2.9)$ & $4(4.9)$ & 0.47 \\
\hline CVA & $13(4.5)$ & $3(2.1)$ & $4(4.9)$ & 0.26 \\
\hline TIA/RIND & $3(1.1)$ & $1(0.7)$ & $0(0)$ & $>0.99$ \\
\hline Confusion & $19(6.6)$ & $5(3.6)$ & $10(12.4)$ & 0.01 \\
\hline In-hospital mortality & $23(8.0)$ & $3(2.1)$ & $5(6.2)$ & 0.15 \\
\hline 30 day mortality & $19(6.6)$ & $3(2.1)$ & $3(3.7)$ & 0.67 \\
\hline 1 yr mortality & $36(12.5)$ & $11(7.9)$ & $9(11.1)$ & 0.42 \\
\hline 5 yr mortality & $60(20.9)$ & $22(15.7)$ & $21(25.9)$ & 0.065 \\
\hline
\end{tabular}

Categorical variables shown as $n$ (\%), continuous variables shown as median ( $25^{\text {th }}$ percentile, $75^{\text {th }}$ percentile). ITU, Intensive Treatment Unit; CVA, cardiovascular accident TIA/RIND, transient ischemic attack/reversible ischemic neurologic deficit.

HAAR and TAAR was significantly and dramatically higher in nonelective groups versus elective groups (Tables 3 and 4).

In-hospital mortality, 30 day mortality, and 1 year and 5 year survival were not different between elective HAAR and TAAR groups.

We matched the 287 patients by age and gender to the UK population life tables available from the United Kingdom Office of National Statistics (http:// www.ons.gov.uk/). The resulting Kaplan-Meier chart comparing survival is shown in Figure 1. The median follow-up period for aortic arch patients was 2.8 years. Figure 2 and $2 \mathrm{~b}$ show sex- and age- matched survival broken down into elective HAAR and TAAR.

\section{Univariate Analysis}

Table 5 shows the univariate analysis of risk factors for overall survival. Nine perioperative factors were identified to be statistically significant: age at operation $\geq 65$ years $(P=0.007)$, angina class IV $(P=0.005)$, NYHA class $\geq$ III $(P=0.002)$, diabetes $(P=0.038)$, respiratory disease $(P=0.02)$, peripheral vascular disease $(P<0.001)$, preoperative renal dysfunction (defined as patients with a functioning renal transplant and patients with acute or chronic renal failure or insufficiency; $P<0.001$ ), concurrent CABG operation
$(P=0.029)$, circulatory arrest time $>100 \mathrm{~min}(P=$ $0.001)$, and cardiopulmonary bypass time $>450 \mathrm{~min}$ utes $(P<0.001)$.

\section{Multivariate Analysis}

Multivariate analysis of patient risk factors revealed 5 variables independently associated with overall follow-up survival (Table 6): renal dysfunction $[\mathrm{HR}=3.11$; 95\% confidence interval $(\mathrm{Cl})=1.44$ to $6.73 ; P<0.001]$, NYHA class $\geq \mathrm{III}(\mathrm{HR}=2.25 ; 95 \% \mathrm{Cl}=1.38$ to 3.67 ; $P=0.002)$, circulatory arrest time $>100 \mathrm{~min}(\mathrm{HR}=$ 2.92; $95 \% \mathrm{Cl}=1.57$ to $5.43 ; P=0.001)$, peripheral vascular disease $(\mathrm{HR}=2.44 ; 95 \% \mathrm{Cl}=1.25$ to 4.74 ; $P=0.004)$, and concomitant CABG operation (HR = 2.14; $95 \% \mathrm{Cl}=1.20$ to $3.80 ; P=0.008$ ) (Table 3). The c-statistic for the Cox model was 0.72 , indicating an acceptable level of discrimination.

\section{Elephant Trunk Procedures}

A total of 117 patients of the entire cohort (81 elective and 36 nonelective) included either a conventional or frozen elephant trunk. Table 7 shows selected and important clinical outcomes from these procedures. No patients suffered paraplegia following these procedures. 
Table 4. In-Hospital and Follow-up Outcomes in Nonelective Hemi-aortic Arch Repair (HAAR) and Total Aortic Arch Repair (TAAR)

\begin{tabular}{|c|c|c|c|}
\hline Variables & $\begin{array}{l}\text { Nonelective HAAR } \\
(n=30)\end{array}$ & $\begin{array}{l}\text { Nonelective TAAR } \\
(n=36)\end{array}$ & $p$-value \\
\hline Intubation time (hours) & $10(8,24)$ & $27(14,79)$ & 0.03 \\
\hline ITU stay (days) & $4(3,11.5)$ & $5(2,8.5)$ & 0.81 \\
\hline Postoperative stay (days) & $11(8,19)$ & $11(9,19.5)$ & 0.62 \\
\hline Re-intubation & $4(13.3)$ & $3(8.3)$ & 0.69 \\
\hline Prolonged ventilation ( $>48 \mathrm{~h}$ ) & $3(10.0)$ & $7(19.4)$ & 0.33 \\
\hline Acute renal failure & $2(6.7)$ & $8(22.2)$ & 0.10 \\
\hline Deep sternal wound infection & $0(0)$ & $0(0)$ & \\
\hline Reexploration for bleeding & $5(16.7)$ & $3(8.3)$ & 0.45 \\
\hline All stroke & $3(10.0)$ & $5(13.9)$ & 0.72 \\
\hline CVA & $2(6.7)$ & $4(11.1)$ & 0.68 \\
\hline TIA/RIND & $1(3.3)$ & $1(2.8)$ & $>0.99$ \\
\hline Confusion & $1(3.3)$ & $3(8.3)$ & 0.62 \\
\hline In-hospital mortality & $6(20.0)$ & $9(25.0)$ & 0.63 \\
\hline 30 day mortality & 5 (16.7) & $8(22.2)$ & 0.57 \\
\hline $1 \mathrm{yr}$ mortality & 7 (23.3) & $9(25.0)$ & 0.88 \\
\hline 5 yr mortality & $8(26.7)$ & $9(25.0)$ & 0.88 \\
\hline
\end{tabular}

CVA, cardiovascular accident; TIA/RIND, transient ischemic attack/reversible ischemic neurologic deficit.

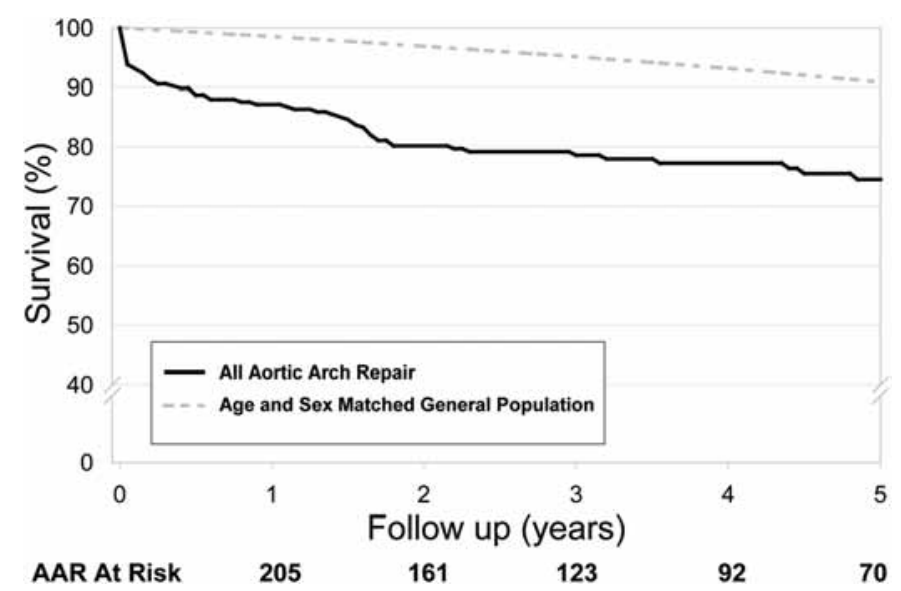

Figure 1. Aortic arch replacement Kaplan-Meier chart with age- and sex-matched general population.

\section{Discussion}

Evolution of surgical techniques and perioperative care has significantly improved morbidity and mortality rates for patients undergoing aortic arch surgery. Whereas early surgical series reported mortality rates that would be prohibitive today [5], recent studies have published rates largely in single figures [1-4]. A number of studies have also published rudimentary survival data demonstrating a beneficial effect of surgery compared to estimated natural history of patients with aortic arch aneu- rysms $[8,9,13]$. The objectives of this study were to: 1) report, compare, and analyze our morbidity and mortality outcomes for hemiarch and total aortic arch surgery; 2) examine the survival benefit of hemiarch and total aortic arch surgery compared to age- and sex-matched controls; and 3) define factors which influence survival in these two groups and, in particular, identify those that are modifiable and potentially actionable.

\section{Characteristics of the Cohort}

The median age of our patients was 63.7 years with $40.1 \%$ being female. Apart from previous cardiac surgery, there were no significant differences in comorbidities between those patients undergoing elective hemiarch and total aortic arch surgery (Table 1). In the nonelective patients, current smoking was significantly more common in the total aortic arch group (6.7\% versus $33.3 \%, P<0.008$; Table 2 ). Of significant interest in our cohort was the presence of symptoms in the form of breathlessness (NYHA class $\geq$ III). Typically, thoracic aortic aneurysms have been thought of as largely asymptomatic. This feature of our cohort is multifactorial. The most likely cause is the high incidence of aortic valve disease with $76.7 \%$ of our entire cohort undergoing aortic valve surgery. In addition to that, $16 \%$ underwent concomitant coronary artery by- 

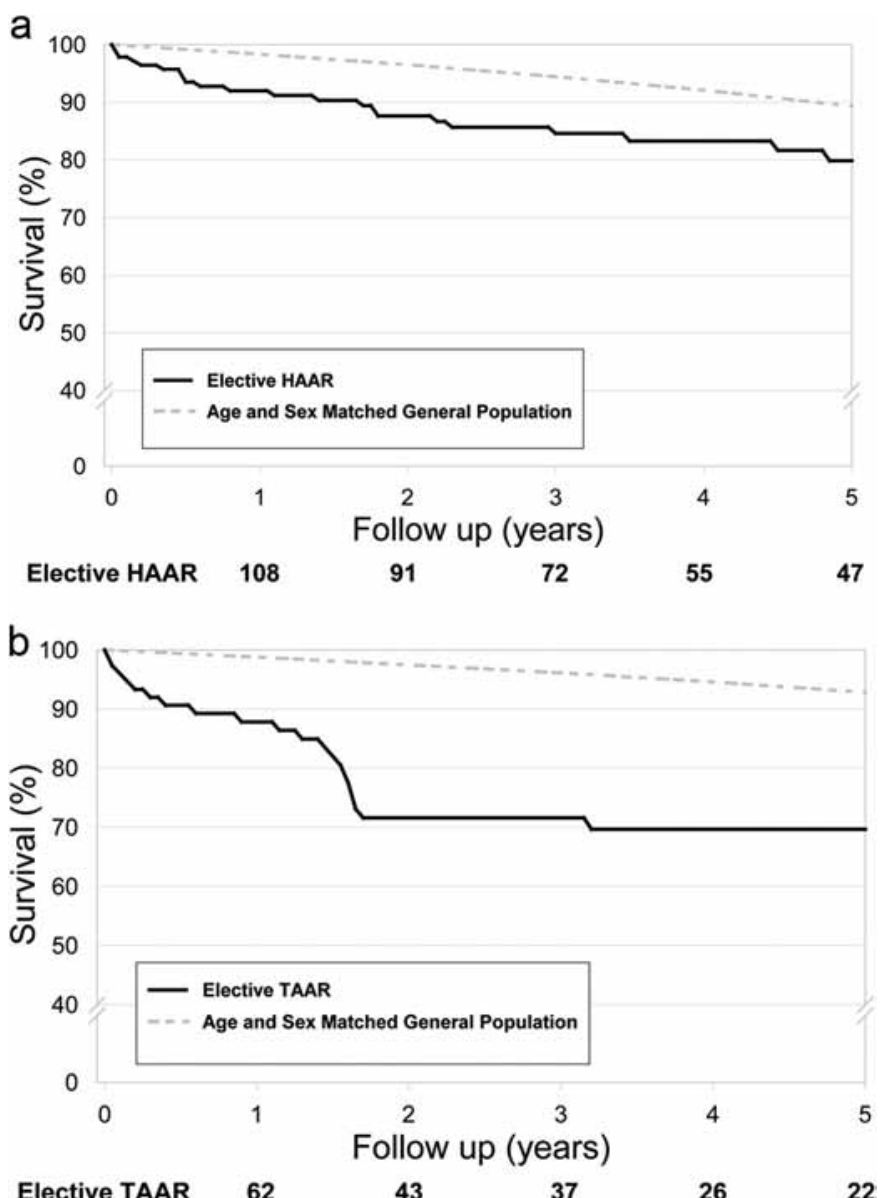

Figure 2. (a) Elective hemi-aortic arch repair (HAAR) chart with age- and sex-matched general population comparator. (b) Elective total hemi-aortic arch repair (TAAR) chart with ageand sex-matched general population comparator.

pass grafting, thus ischemic heart disease had been a likely additional cause of symptoms. Two other characteristics important in conferring symptoms are the left ventricular dysfunction (ejection fraction $<50 \%$ in $20.2 \%$ ) and the incidence of respiratory disease (34.8\%). Current smoking was documented in $13.6 \%$ of the entire group. These data confirm that a good proportion of our patients underwent surgery on both symptomatic and prognostic grounds. This feature is contrary to common dogma that thoracic aortic aneurysm patients are largely asymptomatic, although this is likely true absent the additional factors enumerated above.

\section{Annualized Morbidity and Mortality Outcomes from Aortic Arch Surgery}

The entire cohort of patients (287) undergoing some form of aortic arch surgery under deep hypo- thermic circulatory arrest had an in-hospital mortality of $8 \%$ and stroke rate of $5.6 \%$. Other key outcome measures were prolonged ventilation (12.2\%), acute renal failure $(7.3 \%)$, reexploration for bleeding $(6.3 \%)$, and deep sternal wound infection (0.4\%). Stroke rate in the entire group was $5.6 \%$ with an additional $1.1 \%$ suffering TIA and $6.6 \%$ confusion.

Our institution has developed a "Quality Outcomes Framework" (QOF), broadly based on Society of Thoracic Surgeons (STS) Quality Performance Measures in cardiac surgery (www.sts.org/quality), for internal reporting of annualized data from aortic arch surgery. Unlike the STS measures, which include indicators of process, structure, and outcome, our QOF concentrates on outcomes, annualized, and is presented as a "Statistical Process Control Chart" (Appendices). These include in-hospital mortality, 30 day mortality and 1 year mortality, stroke, reexploration, postoperative renal failure, and prolonged ventilation. This mechanism allows us to monitor the stability of our outcomes annually and investigate and modify processes when deviation is observed. These data are presented in Appendices and not only demonstrate our increasing annual activity over time but also the relative stability of outcomes with little influence of the change in service provision from 2007 (see Methods). Stability of outcomes, particularly major morbidity and mortality, is an important platform for interpreting our survival data and the influences on it.

An interesting aspect of our outcomes is seen when the elective hemiarch and total arch cohorts are examined separately. There were no significant differences in our QOF measures of in-hospital mortality, 30 day mortality, 1 year mortality, prolonged ventilation, acute renal failure, reexploration bleeding, or stroke (Table 3). Even more surprising, although the absolute differences in these two groups within the nonelective cohort were significantly different (Table 4), the relative difference between hemiarch and total arch were nonsignificant. This has informed our consent process and operative strategies. It gives assurance that organ protection strategies are sufficiently robust to allow resection of the total arch where indicated, at the price of a small but nonsignificantly higher morbidity and mortality.

\section{Survival Outcomes}

Age- and sex-matched survival. Our data as an entirety show that survival following some form of aortic arch surgery, under hypothermic circulatory arrest, 
Table 5. Univariate Analysis Showing Significant Risk Factors For Follow-up Survival in All Aortic Arch Repair (AAR) Patients

\begin{tabular}{|c|c|c|c|c|c|c|}
\hline \multirow[b]{2}{*}{ Variables } & \multirow[b]{2}{*}{ Patients $(n)$} & \multirow{2}{*}{$\begin{array}{l}\text { Median follow-up } \\
\text { (months) }\end{array}$} & \multicolumn{3}{|c|}{ Survival rate (\%) } & \multirow[b]{2}{*}{$p$-value } \\
\hline & & & 1 Year & 3 Years & 5 Years & \\
\hline Total & 287 & 33.4 & 87.5 & 80.8 & 79.1 & \\
\hline \multicolumn{7}{|c|}{ Age at operation (years) } \\
\hline$\leq 65$ & 155 & 35.3 & 90.3 & 85.2 & 84.5 & \\
\hline$>65$ & 132 & 27.2 & 84.1 & 75.8 & 72.7 & 0.007 \\
\hline \multicolumn{7}{|c|}{ NYHA class $\geq \mathrm{III}$} \\
\hline No & 211 & 33.8 & 89.1 & 84.4 & 83.4 & \\
\hline Yes & 76 & 29.7 & 82.9 & 71.1 & 67.1 & 0.002 \\
\hline \multicolumn{7}{|l|}{ Diabetes } \\
\hline No & 271 & 34.8 & 88.2 & 81.9 & 80.1 & \\
\hline Yes & 16 & 14.8 & 75 & 62.5 & 62.5 & 0.038 \\
\hline \multicolumn{7}{|c|}{ Respiratory disease } \\
\hline No & 187 & 31.6 & 89.3 & 84.5 & 84 & \\
\hline Yes & 100 & 35.3 & 84 & 74 & 70 & 0.02 \\
\hline \multicolumn{7}{|c|}{ Peripheral vascular disease } \\
\hline No & 266 & 34.5 & 88.4 & 82.3 & 81.2 & \\
\hline Yes & 21 & 25.6 & 76.2 & 61.9 & 52.4 & $<0.001$ \\
\hline \multicolumn{7}{|c|}{ Preoperative renal dysfunction } \\
\hline No & 270 & 35.4 & 89.6 & 82.6 & 80.7 & \\
\hline Yes & 17 & 6 & 52.9 & 52.9 & 52.9 & $<0.001$ \\
\hline \multicolumn{7}{|c|}{ Concomitant CABG procedure } \\
\hline No & 241 & 33.8 & 89.6 & 83.4 & 81.7 & \\
\hline Yes & 46 & 28.4 & 76.1 & 67.4 & 65.2 & 0.029 \\
\hline \multicolumn{7}{|c|}{ Circulatory arrest (minutes) } \\
\hline$\leq 100$ & 251 & 37.5 & 88.8 & 83.3 & 81.3 & \\
\hline$>100$ & 36 & 18.8 & 77.8 & 63.9 & 63.9 & 0.001 \\
\hline \multicolumn{7}{|c|}{ Cardiopulmonary bypass (minutes) } \\
\hline$\leq 450$ & 251 & 35.1 & 90.4 & 84.5 & 82.5 & \\
\hline$>450$ & 36 & 19.3 & 66.7 & 55.6 & 55.6 & $<0.001$ \\
\hline
\end{tabular}

Table 6. Multivariable Analysis Showing Risk Factors for Follow-up Survival in All Aortic Arch Repair (AAR) Patients

\begin{tabular}{lllr}
\hline & Hazard & & \\
Risk factors & ratio & $95 \% \mathrm{Cl}$ & $p$-value \\
\hline Preoperative renal dysfunction & 3.11 & $1.44,6.73$ & $<0.001$ \\
NYHA class $\geq$ III & 2.25 & $1.38,3.67$ & 0.002 \\
Circulatory arrest time $>100$ min & 2.92 & $1.57,5.43$ & 0.001 \\
Peripheral vascular disease & 2.44 & $1.25,4.74$ & 0.004 \\
Concomitant CABG operation & 2.14 & $1.20,3.80$ & 0.008 \\
\hline c-index $=0.72$. & & &
\end{tabular}

matched to age and sex of the UK population (Fig. 1), is parallel beyond 2 years with a disparity of approximately 20\%. The reasons underlying this effect at 2 years are seen in Figure 2 and $2 \mathrm{~b}$. These figures demonstrate survival in hemiarch and total aortic arch groups matched by age and sex. While the hemiarch group survival is fairly flat and parallel with controls, separated by $10 \%$, the survival in total aortic arch patients is somewhat different, albeit on an expanded $Y$-axis. Survival in the total aortic arch group drops off quickly over the first 24 months to approximately $70 \%$ and then remains fairly flat out to 5 years. In absolute terms, the 5 year survival of $70 \%$ is comparable with other published series $[8,9,13]$; however, the shape of the survival curve for this subset of patients of ours is unusual. The Safi group [8] reported a $72 \%$ and $71 \%$ survival at 5 and 10 years, respectively, from 1991 to 2001. A separate report from the Mount Sinai group [1] described long-term survival in 206 aortic arch patients, reporting a 6 year survival rate of $75 \%$. In a large study of 721 patients followed over 17 years, Patel et al. [9] reported survival at 5 years to be $80 \%$, 
Table 7. Elephant Trunk (ET) Postoperative Complications

\begin{tabular}{lccr} 
& \multicolumn{2}{l}{ Total arch replacement } & \\
\cline { 2 - 3 } & $\begin{array}{l}\text { Elective } \\
\text { Variable }\end{array}$ & $\begin{array}{l}\text { Nonelective } \\
(n=81)\end{array}$ & \\
\hline Conventional ET & $37(49.3)$ & $13(37.1)$ & 0.23 \\
Stroke & $2 / 37(5.4)$ & $1 / 13(7.7)$ & $>0.99$ \\
In-hospital mortality & $4 / 37(10.8)$ & $1 / 13(7.7)$ & $>0.99$ \\
30 day mortality & $3 / 37(8.1)$ & $1 / 13(7.7)$ & $>0.99$ \\
Frozen ET & $7(9.3)$ & $5(14.3)$ & 0.52 \\
Stroke & $0 / 7(0)$ & $0 / 5(0)$ & - \\
In-hospital mortality & $0 / 7(0)$ & $1 / 5(20.0)$ & 0.42 \\
30 day mortality & $0 / 7(0)$ & $1 / 5(20.0)$ & 0.42 \\
Reverse ET (2nd stage) & $2(2.7)$ & $0(0)$ & $>0.99$ \\
Stroke & $0 / 2(0)$ & $0(0)$ & - \\
In-hospital mortality & $0 / 2(0)$ & $0(0)$ & - \\
30 day mortality & $0 / 2(0)$ & $0(0)$ & - \\
\cline { 1 - 2 } & & &
\end{tabular}

Categorical variables shown as $n(\%)$; comparisons made with $\chi^{2}$ and Fisher's exact tests as appropriate.

with 10 and 12 year survival of $65 \%$ and $51 \%$, respectively. Our captured follow-up data systems do not allow us to easily determine the cause of this early attrition in our total arch cohort. Future enquiry will focus on causes of early death in this group and act as a focus of effort to identify modifiable risk factors. For the present, these data allow us to better inform the consent process.

\section{Univariate and multivariate analysis of survival}

Univariate analysis of the entire cohort found significant relationships between survival and age (65 years), NYHA class $\geq$ III, diabetes, respiratory disease, peripheral vascular disease, renal dysfunction, concomitant CABG, circulatory arrest time ( $>100 \mathrm{~min}$ ) and cardiopulmonary bypass ( $>450 \mathrm{~min}$ ). Multivariate analysis demonstrated that independent factors associated with survival were renal dysfunction (HR 3.11), NYHA class $\geq$ III (HR 2.25), circulatory arrest time (> 100 min; HR 2.92), peripheral vascular disease (HR 2.44), and concomitant CABG (HR 2.14).

Safi's group [8] identified increasing age, chronic obstructive pulmonary disease, concurrent unoperated aneurysm, arch involvement, pump time, concurrent aortic valve replacement, and postoperative renal failure to negatively affect survival following aortic arch repair. Interestingly, Crawford's group, of which Safi was a part, published a similar paper on influences on survival in 1989 [13], showing independent predic- tors of follow-up survival were: aneurysm symptoms, preoperative angina, extent of proximal replacement, associated residual distal aneurysm, balloon pump, renal dysfunction, cardiac dysfunction, and stroke. Several predictors of late mortality identified by Patel et al. [9] included increasing age, preoperative renal function, history of CABG or descending aortic replacement, prolonged circulatory arrest time, and postoperative tracheostomy.

\section{Independent influences on survival}

NYHA class $\geq I I I$. The finding of NYHA class $\geq I I I+$ as an independent risk factor for survival (HR 2.25, $P<$ 0.002 ) is most likely a surrogate marker for a multitude of pathologies underlying this symptom-a composite variable-which independently are not significant. These include aortic valve disease, ischemic heart disease, impaired left ventricular function, and respiratory disease. By far, the largest proportion of patients, however, required aortic valve replacement, but this did not come out as an independently significant variable with respect to survival. A recent study examining NYHA class at the time of aortic valve repair (AVR) for severe aortic stenosis [14] demonstrated that patients with NYHA III-IV had significantly impaired short- and long-term survival compared to those with NYHA I-II, even with preserved left ventricular function. Ischemic heart disease, ventricular dysfunction, and respiratory compromise might all be expected to negatively impact prognosis independent of aortic disease. A study by Leavitt et al. 2006 [15] has shown that in patients who have undergone CABG, survival over 10 years is significantly impaired in those patients with a diagnosis of COPD. Similarly, survival has been shown to be impacted by ischemic heart disease and ventricular dysfunction [16]. Unlike most series, a good proportion of our patients were symptomatic from concomitant disease rather than aneurysm per se, and these data suggest that earlier intervention before development of symptoms is appropriate. Interestingly, Crawford's original series [13] did demonstrated the presence of symptoms in the form of angina as an independent variable in long-term survival following aortic arch surgery. Preoperative investigation and aggressive optimization of causes of breathlessness may represent an opportunity to improve not only perioperative morbidity and mortality, but also longer-term survival in these patients. 
Postoperative renal dysfunction. Preoperative renal impairment has the highest hazard ratio in our multivariate model $(3.11, P<0.0001)$ of risk factors for follow-up survival. A recent study [17] in which a large cohort of patients undergoing cardiac surgery, including aortic surgery, were examined for a relationship between renal impairment and survival showed that, preoperative renal dysfunction is a predictor of longterm mortality in cardiac surgery patients. Indeed, in a large series of aortic patients presented by Patel et al. [9], preoperative renal impairment was an independent predictor of survival. In the original Crawford series [13], renal dysfunction was a significant variable. Interestingly, Estrera et al. [8], in 2002, found postoperative renal failure but not preoperative renal impairment as a risk factor for follow-up survival. Certainly, Loef et al. [18], in 2005, drew a similar conclusion in a large series of patients undergoing cardiac surgery: immediate postoperative renal function deterioration in cardiac surgical patients predicts in-hospital mortality and long-term survival (HR 1.83). While postoperative renal failure and its relationship to survival are, of course, interesting, this points us to providing excellent preoperative and postoperative care. Preoperative renal impairment and its relationship to survival offer us an opportunity to modify and improve the health status of the patient with a view to improving long-term survival. Taken together, evidence suggests that meticulous attention to modifying or maintaining renal function in the perioperative period is crucial to long-term survival.

Circulatory arrest time $>100 \mathrm{~min}$. Intuitively, prolonged periods of circulatory arrest will cause significant physiological distress. Indeed, numerous studies have discussed durations of circulatory arrest as significant predictors of death and morbidity such as stroke, many of these summarized in systematic reviews $[10,19,20]$. Such morbidity will of course have consequences for survival. While prolonged circulatory arrest times may simply reflect complex anatomy and pathologies such as acute Type A dissection, chronic Type A dissection or infective processes, these times are also determined by the orchestration of the operation in terms of early distal body perfusion, use of various branched configurations for arch vessels, or the Carrel patch technique. The definition of the circulatory arrest time is also important in understanding and interpreting studies. In this study, we have taken circulatory arrest time as the time taken to reestablish distal body perfusion. In the case of hemiarch, this definition is easily understood as completion of the anastomosis is the point of return of distal body perfusion and cerebral perfusion. When total arch with Carrel patch is employed, again, the definition is easily understood as completion of the distal anastomosis and patch is the point at which distal and cerebral perfusion is established. However in total arch replacement, when separate branches were employed, distal perfusion was reestablished on completion of the distal anastomosis. Each head vessel was then anastomosed sequentially with ongoing anterograde cerebral perfusion, and in these cases, the circulatory arrest time was less than the "assisted cerebral perfusion time" by the duration of time it took to reanastomose 1-3 cerebral vessels. In terms of modifiable risk factors, the more frequent use of individual branches as opposed to a Carrel patch has allowed us to reduce our circulatory arrest times, although we have yet to see this translate into survival benefit. We have not yet acquired an easy, safe, and reproducible mechanism to establish distal perfusion during construction of the distal anastomosis, but this would effectively reduce circulatory arrest time further, as defined in our series.

Peripheral vascular disease. With the exception of one small study of 62 patients, which revealed that peripheral vascular disease was significantly associated with transient neurological dysfunction following arch surgery [21], little has been published. This may be because of the small number of patients with peripheral vascular disease in other studies, and even with our patient cohort, only $7.3 \%$ were found to have peripheral vascular disease. Clearly, atherosclerotic burden might be expected to influence follow-up survival. A study by Kurra et al. [22] studied computed tomography imaging data on 862 patients undergoing cardiac surgeries and quantified a "plaque burden score." They concluded that the extent of thoracic atheroma burden is independently associated with increased long-term mortality in patients following cardiothoracic surgery. This again provides opportunity to modify survival by careful investigation and treatment of peripheral vascular disease both preoperatively and postoperatively.

Concomitant CABG operation. In our study, $16 \%$ of patients underwent concomitant CABG. A number of previous studies have described outcomes from concomitant CABG and aortic surgery. As far back as 2002, 
Hitoshi Yokoyama [23] summarized the outcomes of 6 studies between 1989 and 2001 demonstrating higher operative mortality and morbidity from concomitant CABG. Our study demonstrates that concomitant CABG is not associated with higher operative mortality but is associated with worse postoperative follow-up survival, with a hazard ratio of $2.14(P<0.008)$. There is a wealth of data from numerous studies demonstrating that concomitant CABG at the time of AVR is negatively associated with survival $[23,24]$, and data from the Bristol group [25] have reported reduced 3 year survival in patients undergoing concomitant CABG at the time of ascending/arch surgery. Coronary grafting at the time of aortic arch surgery is required for symptomatic reasons and to aid myocardial protection at the time of surgery; it does not, however, appear to be associated with prognostic benefit. On the face of it, this does not appear to be a modifiable risk factor coming into surgery.

\section{Managing Perioperative Risk Factors for Long-term Survival- "Primary and Secondary Prophylaxis"}

Good long-term survival does not just happen. Careful attention is required to modifiable risk factors preoperatively, and the best possible pre- and postoperative care is crucial. Care for these patients should not end on discharge from hospital. Lifelong follow-up and attention to ongoing secondary prophylaxis is important.

\section{Conclusions}

Morbidity, mortality, and medium-term survival were not statistically different for patients undergoing elective hemi-aortic arch and total aortic arch surgery. The survival curve in this group of patients is flat and parallel to sex- and age-matched controls beyond 2 years. Multivariate analysis identified independent influences on survival as renal dysfunction, NYHA class $\geq \mathrm{III}$, circulatory arrest time ( $>100$ min), peripheral vascular disease, and concomitant CABG. Focus on preoperative optimization of some of these variables may positively influence longterm survival.

\section{Conflict of Interest}

The authors have no conflict of interest relevant to this publication.

Comment on this Article or Ask a Question

\section{References}

1. Estrera AL, Miller CC 3rd, Lee TY, Shah P, Safi $\mathrm{HJ}$. Ascending and transverse aortic arch repair. Circulation. 2008;118:S160-S166. 10. 1161/CIRCULATIONAHA.107.757419

2. LeMaire $S A$, Price $M D$, Parenti $J$, Johnson $M L$, Lay $A D$, Preventza $O$, et al. Early outcomes after aortic arch replacement by using the Y-graft technique. Ann Thorac Surg. 2011;91:700-708. 10.1016/j.athoracsur.2010. 11.008

3. Ma WG, Zhu JM, Zheng J, Liu YM, Ziganshin BA, Elefteriades JA, et al. Sun's procedure for complex aortic arch repair: total arch replacement using a tetrafurcate graft and stented elephant trunk implantation. Ann Cardiothorac Surg 2013;2:642-648. 10.3978/ j.issn.2225-319X.2013.09.03

4. Thomas M, Li Z, Cook DJ, Greason KL, Sundt TM. Contemporary results of open aortic arch surgery. J Thorac Cardiovasc Surg. 2012;144:838-844. 10.1016/j.jtcvs. 2011.09.069

5. Griepp RB, Stinson EB, Hollingsworth JF, Buehler D. Prosthetic replacement of the aortic arch. J Thorac Cardiovasc Surg. 1975; 70:1051-1063.

6. Coselli JS, LeMaire SA. Aortic arch surgery: principles, strategies and outcomes, Ed 1. London: Blackwell Publishing Ltd, 2008.

7. Svensson LG, Adams DH, Bonow RO, Kouchoukos NT, Craig Miller D, O'Gara PT, et al. Aortic valve and ascending aorta guidelines for management and quality measures. Ann Thorac Surg. 2013;95:1-66. 10.1016/j. athoracsur.2012.11.025

8. Estrera AL, Miller CC 3rd, Huynh TT, Porat EE, Safi HJ. Replacement of the ascending and transverse aortic arch: determinants of longterm survival. Ann Thorac Surg 2002;74: 1058-1065.

9. Patel HJ, Deeb GM. Open aortic arch reconstruction. Ann Cardiothorac Surg. 2013;2: 181-183. 10.3978/j.issn.2225-319X.2013.02. 07.

10. Yan TD, Bannon PG, Bavaria J, Coselli JS, Elefteriades JA, Griepp RB, et al. Consensus on hypothermia in aortic arch surgery. Ann Cardiothorac Surg. 2013;2:163-168. 10.3978/ j.issn.2225-319X.2013.03.03
11. Hiratzka LF, Bakris GL, Beckman JA, Bersin RM, Carr VF, Casey DE Jr, et al. Guidelines for the diagnosis and management of patients with thoracic aortic disease. Circulation. 2010;121:e266-e369. 10.1161/CIR. Ob013e3181d4739e

12. Kaplan E, Meier P. Nonparametric estimation from incomplete observations. J Am Stat Assoc 1958;53:547-581.

13. Crawford ES, Svensson LG, Coselli JS, Safi $\mathrm{HJ}$, Hess KR. Surgical treatment of aneurysm and/or dissection of the ascending aorta, transverse aortic arch and ascending aorta and transverse arch. Factors influencing survival in 717 patients. J Thorac Cardiovasc Surg. 1989;98:659-673.

14. Piérard $S$, de Meester $C$, Seldrum $S$, Pasquet A, Gerber B, Vancraeynest D, et al. Impact of preoperative symptoms on postoperative survival in severe aortic stenosis: implications for the timing of surgery. Ann Thorac Surg. 2014;97:803-809. 10.1016/j.athoracsur. 2013.08.059

15. Leavitt BJ, Ross CS, Spence B, Surgenor SD, Olmstead EM, Clough RA, et al. Long term survival of patients with chronic obstructive 
pulmonary disease undergoing coronary artery bypass surgery. Circulation. 2006;114: 1430-1434. 10.1161/CIRCULATIONAHA.105. 000943

16. Emond M, Mock MB, Davis KB, Fisher LD, Holmes DR Jr, Chaitman BR, et al. Long-term survival of medically treated patients in the Coronary Artery Surgery Study (CASS) Registry.Circulation.1994;90:2645-2657.10.1161/ 01.CIR.90.6.2645

17. Dhanani J, Mullany DV, Fraser JF. Effect of preoperative renal function on long-term survival after cardiac surgery. J Thorac Cardiovasc Surg. 2013;146:90-95.10.1016/j.jtcvs. 2012.06.037

18. Loef BG, Epema AH, Smilde TD, Henning RH, Ebels T, Navis G, et al. Immediate postoperative renal function deterioration in cardiac surgical patients predicts in-hospital mortality and long-term survival. J Am Soc Nephrol. 2005;16:195-200. 10.1681/ASN. 2003100875

19. Ziganshin BA, Elefteriades JA. Deep hypothermic circulatory arrest. Ann Cardiothorac
Surg. 2013;2:303-315. 10.3978/j.issn.2225319X.2013.01.05

20. Tian DH, Wan B, Bannon PG, Misfield M, Lemaire SA, Kazui T, et al. A meta-analysis of deep hypothermic circulatory arrest alone versus with adjunctive selective anterograde cerebral perfusion. Ann Cardiothorac Surg. 2013;2:261-270. 10.3978/j.issn.2225-319X. 2013.05.11

21. Matalanis G, Hata M, Buxton BF. A retrospective comparative study of deep hypothermic circulatory arrest, retrograde and anterograde cerebral perfusion in aortic arch surgery. Ann Thorac Cardiovasc Surg. 2003;9: 174-179.

22. Kurra V, Lieber ML, Sola S, Kalahasti V, Hammer D, Gimple S, et al. Extent of thoracic aortic atheroma burden and long-term mortality after cardiothoracic surgery: a computed tomography study. JACC CardiovasC Imaging. 2010;3:1020-1029. 10.1016/j.jcmg. 2010.08 .006

23. de Waard GA, Jansen EK, de Mulder M, Vonk $A B$, Umans $V A$. Long term outcomes of isolated aortic valve replacement and concom- itant AVR and coronary artery bypass grafting. Neth Heart J. 2012;20:110-117. 10.1007/ s12471-011-0238-6

24. Jones JM, Lovell D, Cran GW, Macgowan SW. Impact of coronary artery bypass grafting on survival after aortic valve replacement. Interact Cardiovasc Thorac Surg. 2006;5:327-330. 10.1510/icvts.2005.118349

25. Narayan $P$, Rogers $C A$, Caputo $M$, Angelini $G D$, Bryan AJ. Influence of concomitant coronary bypass graft on outcome of surgery of the ascending aorta/arch. Heart. 2007;93: 232-237. 10.1136/hrt.2006.090860

Cite this article as: Bashir $M$, Field $M$, Shaw M, Fok M, Harrington D, Kuduvalli $M$, Oo A. Influences on Early and Medium-Term Survival Following Surgical Repair of the Aortic Arch. Aorta 2014;2(2): 56-73. DOI: http://dx.doi.org/10.12945/ j.aorta.2014.13-040 
Appendix: Annualized Outcomes of Key Quality Indicators over Study Period

Annual in-hospital mortality rate in elective aortic arch patients

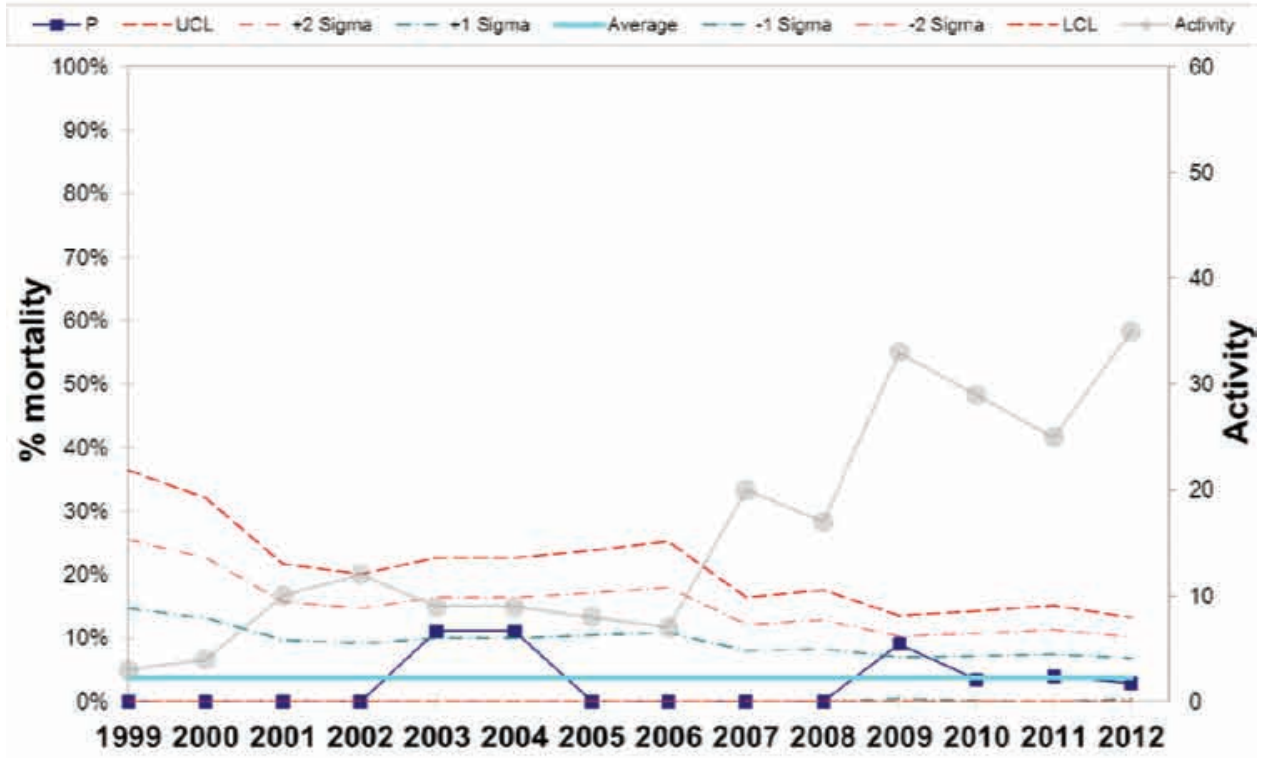

Annual 1-year mortality rate in aortic arch patients

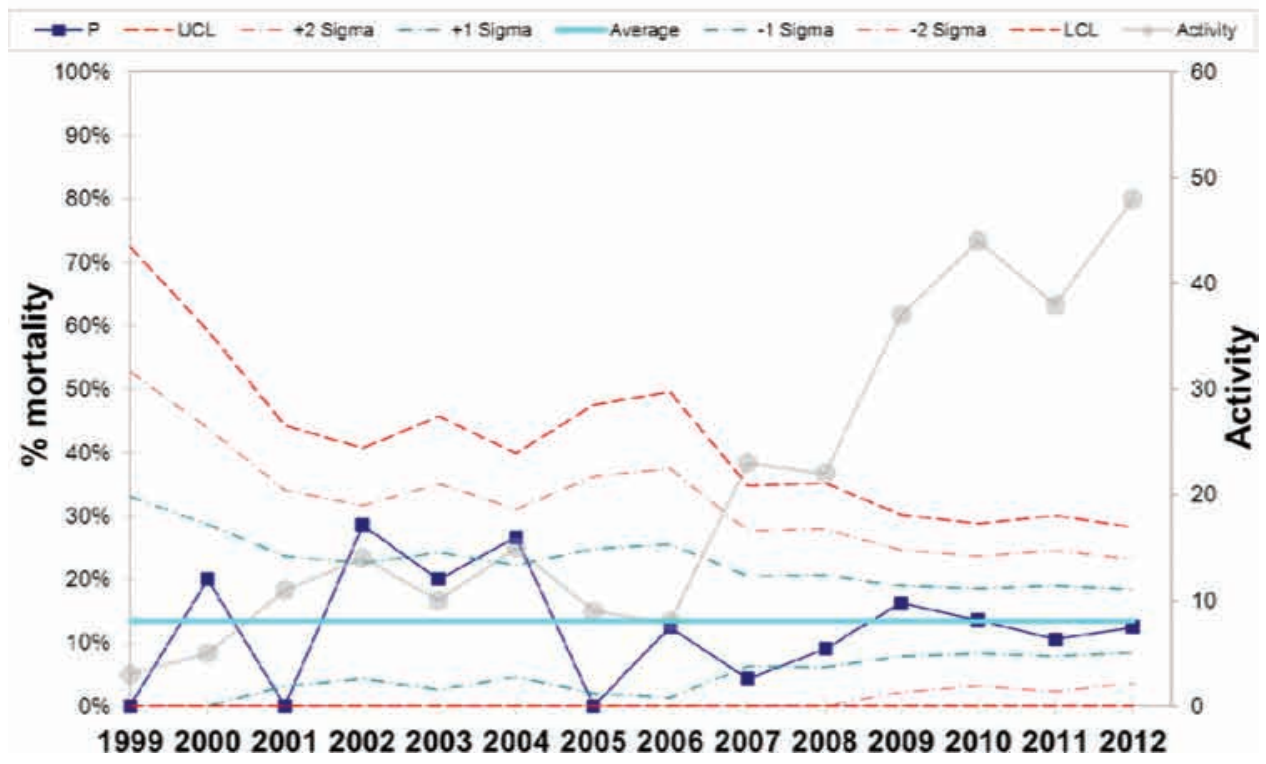


Annual stroke rate in aortic arch patients

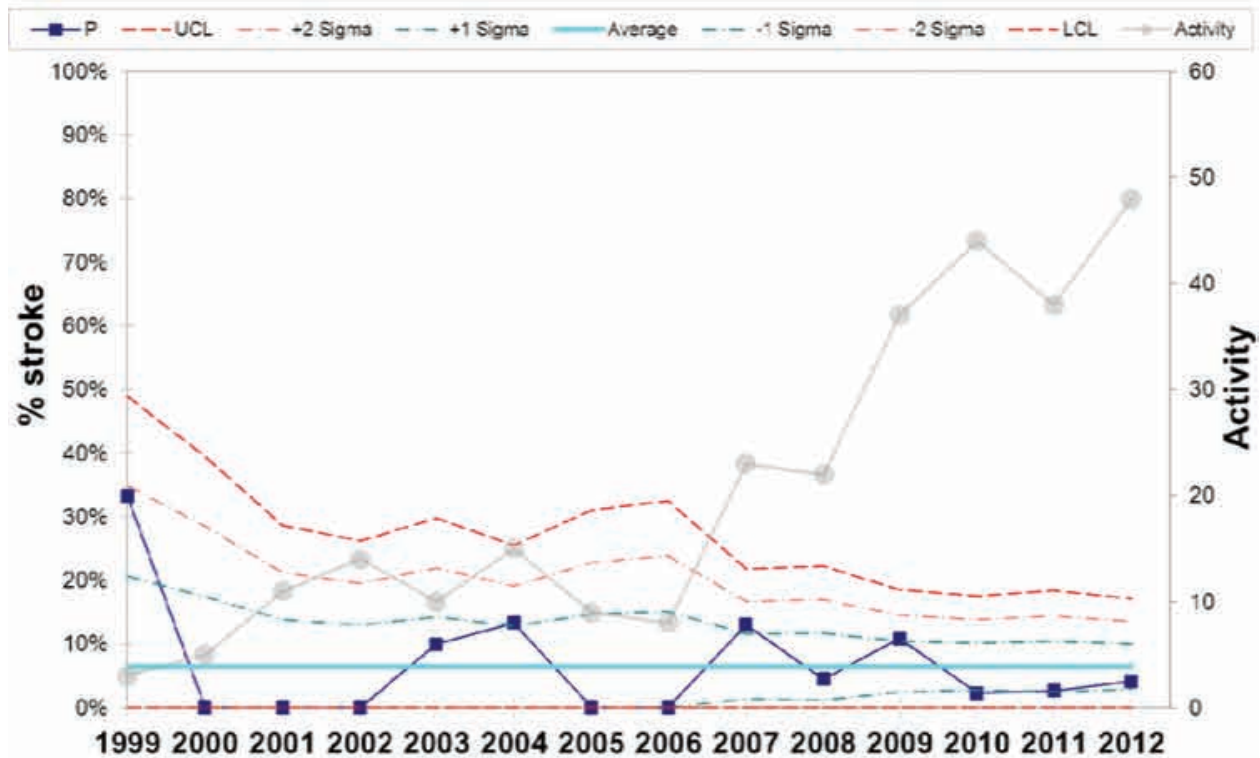

Annual post-operative renal failure rate in aortic arch patients

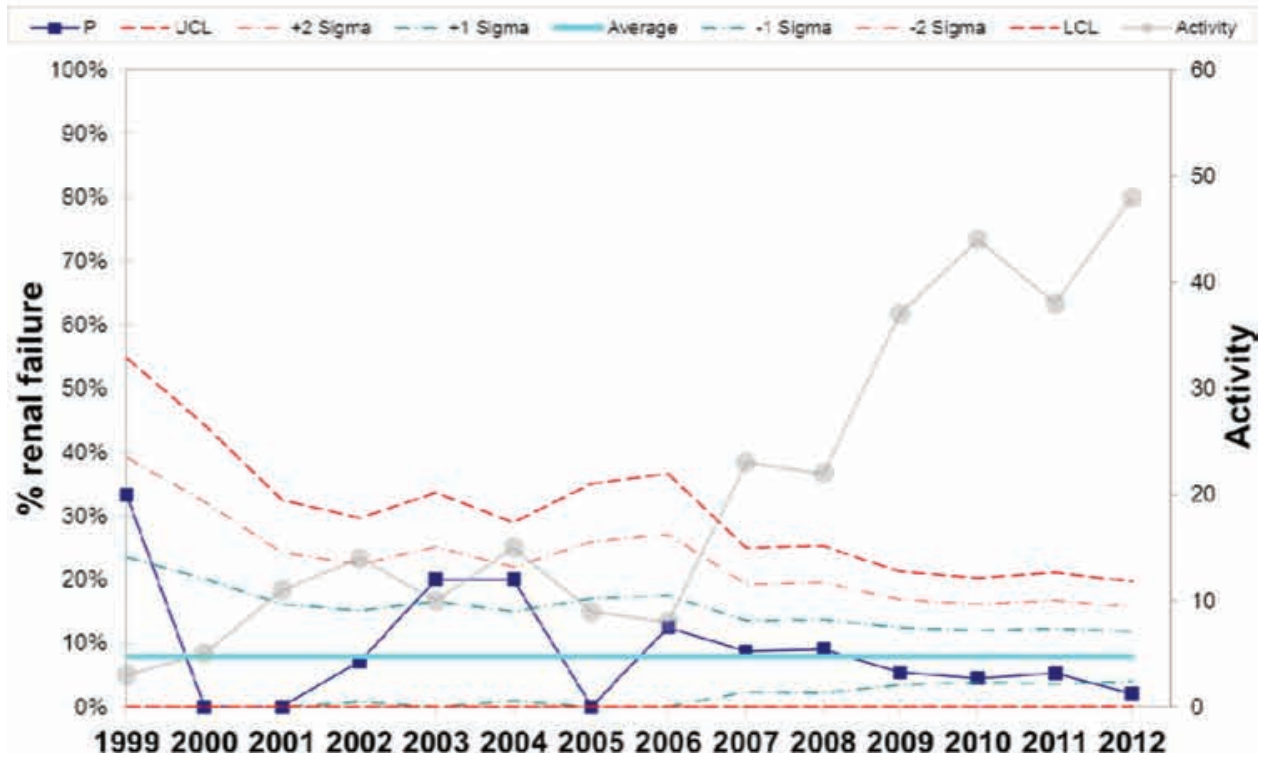


Annual reoperation for bleeding rate in aortic arch patients

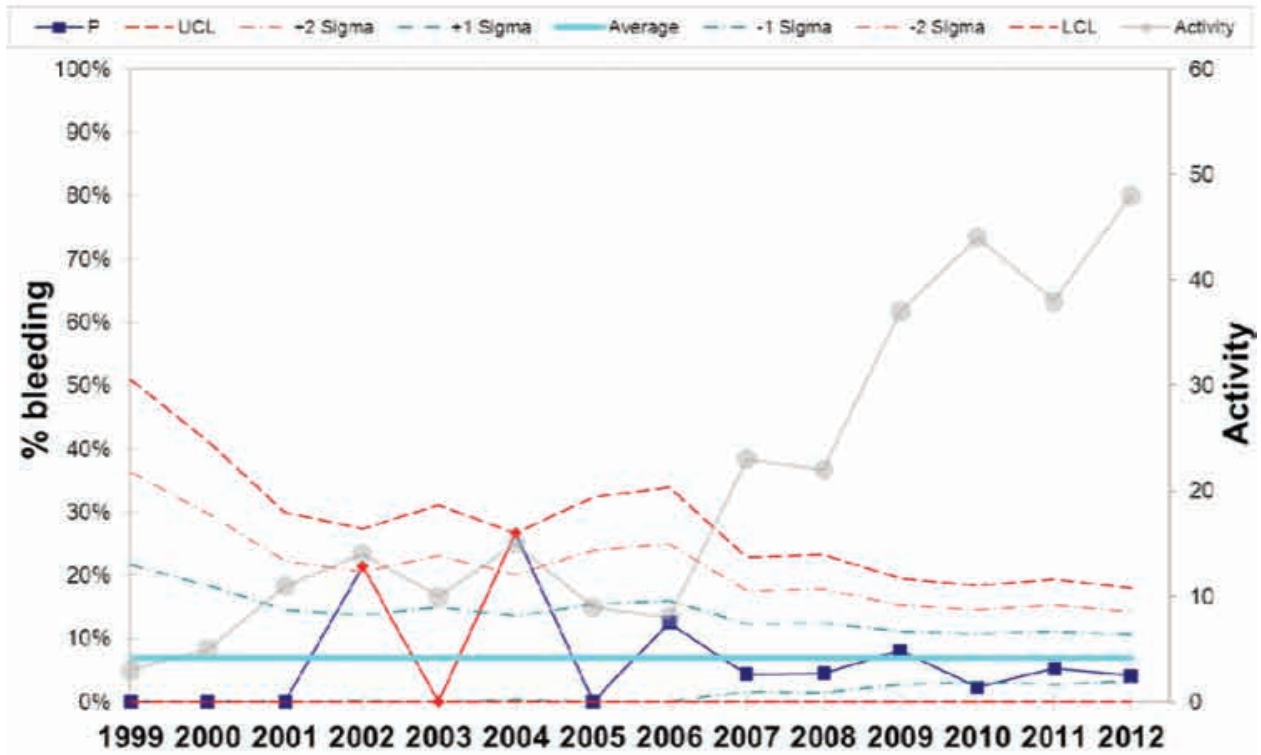

Annual rate of patients ventilated $>48 \mathrm{hrs}$ in aortic arch patients

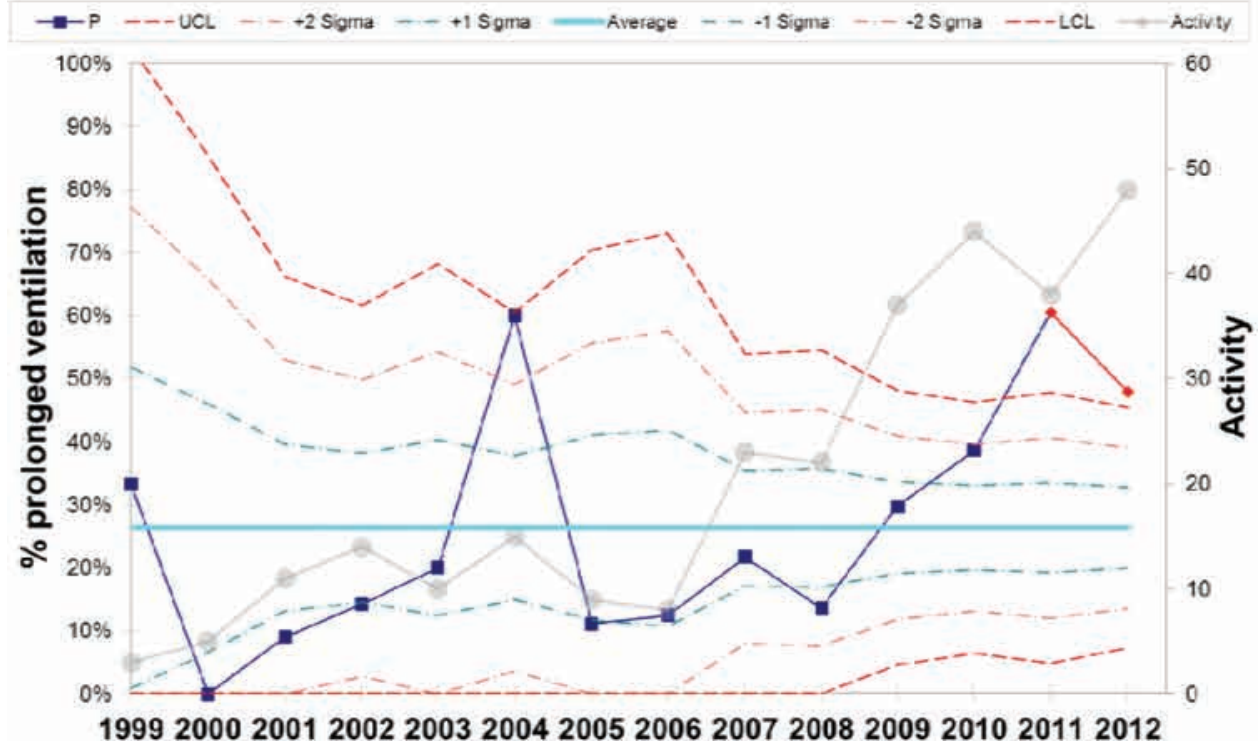

\section{EDITOR'S QUESTIONS}

1. In your discussion, you emphasize that there were no differences in outcomes between hemi-arch and total arch patients, either acutely or in later follow-up. Yet, numerically in-hospital mortality was higher in the total arch group $(6.2 \%$ vs $2.1 \%)$, stroke was higher $(4.9 \%$ vs $2.9 \%)$, renal failure was higher (6.2\% vs $4.3 \%)$, and prolonged ventilation was higher (16.1\% vs $8.6 \%)$. Also, mortality at 5 -years was higher ( $25.9 \%$ vs $15.7 \%)$. Do you think that all the $p$-values for these powerful trends might have been significant if your " $\mathrm{n}$ " was larger?

Although many of the patient outcomes did not achieve statistical significance when comparing total arch to hemi-arch 
operations, they do show a percentage difference that is strongly suggestive of statistical significance given larger sample sizes. The trend towards higher rates of mortality and morbidity in patients undergoing the more invasive total arch procedure is not unexpected, and we would presume that these clinically appropriate differences would result in a $p$ value $<$ 0.05 in series with greater activity.

2. You usefully identify predictors of poor long-term survival after aortic arch replacement (NYHA Class $\geq 3$, preoperative renal dysfunction, long circulatory arrest time, presence of peripheral vascular disease, and concomitant (ABG). Do you really think we can improve long-term outcome by optimizing these factors? Circulatory arrest is a matter of technical ability, or the anatomy. Breathing issues, asthma, peripheral vascular disease, and concomitant CAD are all comorbidities, largely beyond our control. You have identified these important predictors, but influencing them beneficially is another story. Please comment.

General optimization of patients prior to major aortic surgery is key to reducing risk of mortality and immediate post-operative morbidity. Enhanced recovery requires a close scrutiny of comorbitities such as LV function, renal impairment, respiratory disease and nutrition and where possible optimization either preoperatively or perioperatively. Our paper identifies factors associated with longterm survival. Identifying these and attempting to optimize will not only help reduce operative risk but also possibly improve survival. NYHA Class does reflect issues such as poor LV function, valve, coronary and respiratory disease, all of which may be addressed to some degree. Renal impairment may be addressed depending on etiology. Circulatory arrest time may be reduced by measures such as branched grafts, augmented cerebral perfusion and distal perfusion.

We simply aim to identify factors that may be scrutinized preoperatively as part of an enhanced recovery program improving immediate and long-term outcomes. Out intention is to look beyond simply good mortality outcomes and low incidence of markers of key quality outcomes, towards longer-term survival. 